\title{
Improving Teacher Development in Rural China: A Case of "Rural Teacher Support Plan"
}

\author{
LIJian | ORCID : 0000-0002-3228-8163 \\ Faculty of Education, Beijing Normal University, Beijing, China \\ jianli2og@bnu.edu.cn
}

\begin{abstract}
Since 2015, both the educational policymakers and practitioners in China passionately have sought to raise the educational quality, especially in Chinese rural schools. Series of significant and instructive reforms were designed to boost educational quality comes from China, where in 2015 the central government enacted an overwhelming educational policy to reform rural teacher development. China's politics on reforming rural teacher development differ from similar reforms elsewhere in Asia countries due to the strong role of centralized top-down power representatives, various types of policy formation pathways and the final consulted settlement with the national and local teacher committees. This study also emphasizes the discussion on the complicated roles of distributive education politics and policy networks in contemporary Chinese education system.
\end{abstract}

\section{Keywords}

educational quality - rural teacher development - teacher education - Chinese education system

\section{Introduction}

What does educational quality mean? Most studies indicate that teaching performance serve a pivotal role for exploring students learning outcomes. (Chetty 
\& Rockoff, 2014; Corcoran, 2007; Guo \& Kilderry, 2018). The promotion in teachers' profession is associated with improving the probability of learning outcomes and the quality of the colleges that students attend. Indeed, students who receive higher quality of education have steeper earnings trajectories $(\mathrm{Li}$, 2019). The effectiveness of the educational policies and other educational inputs depend on the quality of the daily work of teachers (Guo \& Kilderry, 2018; Osler \& Starkey, 2017). In current Chinese education system, Rural Teacher Support Plan ("RTSP") in 2015 totally shaped rural teacher development. The RTSP covers all aspects of a life-long professional development from initial rural teacher preparation to the recruitment, training, and evaluation throughout various career stages. The policy implementation process of conducting this reform was contentious and systematic, but ultimately led to a compromise policy that both national governmental reformers and local provincial administrative practitioners. The RTSP finally passed State Council in December 2014 with most articles approved unanimously, and implementation moved ahead quickly through the following one years of the legal processing (Ministry of Education, 2016).

How were Chinese educational policymakers able to get such an overwhelming education reform enacted? To response it, our key argument is that three main interests groups had major roles, continuatively over time and in descending order of influences: (1) Chinese scholars and experts in the field of rural teacher studies; (2) policy networks in rural teacher education, and (3) the national and local teacher development committees, and legislators in State Council. The various stakeholders provided a strong but general mandate for such educational reform, the policy network added specifics on the main changes to rural teacher development in the educational reform, and the policymakers and scholars negotiated some final adjustments to the proposed educational reform ( $\mathrm{Li}$ et al., 2020). In addition, this study offers relevant social background on these key stakeholders, how they compare to protagonists in education reform elsewhere in current Chinese rural education system, and how they relate to key theoretical approaches to educational equality politics. Then, the core attributes of the rural teacher reform are epitomized to explore the characteristics that were most obvious in reform educational politics regarding to an analysis of their major stakeholders. This analysis explores the policy preferences and actual influence of the key stakeholders. This process-tracing section develops our core arguments about the stakeholders and factors, the policy network, and some legislators - that affected the origins, design, and negotiation of the reforms to rural teaching development. 


\section{Rural Teacher Support Plan (2015-2020) (“RTSP Plan”)1}

The RTSP is a sustainable and comprehensive rural teacher reform. This part briefly shows the key components that existed in the final legislation through analyzing the various alterations the law underwent from initial proposal through sequential revisions in State Council.

The Rural Teacher Support Program $\left(2015^{-2020}\right)$ covers all pre-school and K-12 rural teachers who teach in rural schools that receiving Chinse central government funding support. Previous policies on evaluation and performance pay affected only rural teachers in municipal schools (44 percent of teachers). The RTSP incorporates all rural teachers as well in private-funded schools (47 percent of teachers) and constitutes more centralization and government intervention into the private-voucher sector. Thus, the RTSP covered over 95 percent of teachers and students (See Figure 1).

More specifically, the RTSP is a systemic and integral policy that includes (see Figure 1):

(1) Give priority to recruiting rural teachers in poor areas and increasing the wage subsidies for rural teachers. Improve the living conditions of rural teachers. Fully implement the policy of providing living allowances to

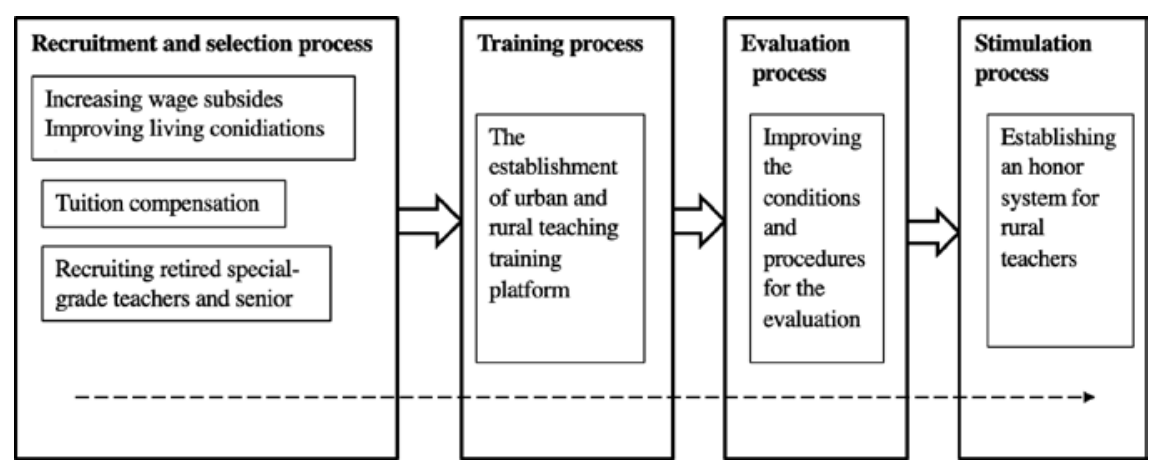

FIGURE 1 A sustainable and integral education policy process of rural teacher development plan

1 On April 1, 2015, the 11th meeting of the central leading group for deepening reform was held and the rural teachers support plan $\left(2015^{-2020}\right)$ was reviewed and approved. Preventing intergenerational transmission of poverty. Developing rural education, so that every rural child can receive a fair and quality education, and preventing the intergenerational transmission of poverty, is a major task that will benefit both the present and future generations. The construction of rural teachers should be placed in the strategic position of priority development. 
rural teachers and continue to give comprehensive awards and subsidies to them from the central government.

(2) College graduates who have obtained the teacher qualification and teach in rural schools for a certain period of time shall enjoy tuition compensation and state policy on student loan compensation in accordance with relevant regulations.

(3) All localities should take effective measures to encourage retired specialgrade teachers and senior teachers from cities and towns to teach in rural schools.

(4) To unify the standards for the establishment of urban and rural teaching training platform. Rural primary and secondary school staff in accordance with the unified verification of urban standards, which village primary schools in accordance with the establishment of the ratio of students and teachers and teachers in combination with the way of verification.

(5) All localities should improve the conditions and procedures for the evaluation of rural teachers' professional titles (posts), so as to achieve an overall balance between the proportion of urban and rural schoolteachers' post structures in counties and truly give preference to rural teachers.

(6) Establish an honor system for rural teachers. The state shall issue certificates of honor to teachers who have taught in rural schools for more than 30 years in accordance with relevant regulations.

The portfolio policy is constructed to guarantee rural teachers to obtain their best pedagogical practices and mainly includes three modules: (1) pedagogical training to improve both the teaching ability and teaching quality of rural teachers; (2) sufficient class hours of training is offered for all rural teachers and principals; and (3) professional evaluation and honor system for rural teachers are designed to stimulate the teaching quality of rural teachers. Rural schools should take effective approaches to encourage retired special-grade teachers and senior teachers from cities and towns to teach in rural schools. If the teaching evaluation perceives the disadvantages, then rural schools could provide accessible teaching training to rural teachers (with Chinese central governmental funding support). This political document also encourages retired special-grade urban senior teachers to teach in rural schools. It also unifies the standards to recruit rural teachers to require them pass the unified verification of teachings standards and then assigns to working in rural publicly funded schools.

Moreover, this teaching training system offers better teaching performance by the means of offering sustainable assessments for their progressive 
professional development. The substantial salaries increase associated with this policy. The RTSP raises starting salaries by a third, and after 16 years teachers at the highest level can earn more than $5^{\circ}$ percent over the previous maximum salary. Promotion through the different steps allows teachers to take on new responsibilities and diversify their roles. Some of these roles are remunerated (for instance to be a mentor), others are associated with non-teaching hours. Thus, there are monetary and non-monetary incentives as teachers progress through the different steps of the system (Ministry of Education, 2016). In order to implement it, the Ministry of Education would cost 53.2billion per year. This constitutes a huge increase in new spending equivalent to o.6 percent of GDP and 8 percent of total public spending (Ministry of Education, 2016). Chinese central government passed a major tax reform in 2015 to raise government revenues by three percent of GDP in order to be able to pay for the RTSP and other ambitious education reforms like free university education for poorer students. In summary, the RTSP provides for higher standards, better training and mentoring, regular evaluations, and stronger incentives and rewards for attracting and retaining talented teachers (Ministry of Education, 2016).

\section{3}

\section{Conclusions and Implications}

The comprehensive and sustainable influences of the RTSP on learning outcomes might take decades to stimulate new rural teachers and receive all the recruitment, training, mentoring, and performance incentives and replace new round assigned rural teachers who entered before the RTSP. However, on the first stage of rural teacher recruitment, recent developments show positive implications. After the 2017 national college entrance exams, more and more students with higher scores would like to choose to pursue pedagogy majors through applicating for national government fellowships as public-funded students studying in normal universities and colleges.

A key education policy lesson from this case is that the complicated compromise and negotiation among State Council presented policymaker, Ministry of Education on behalf of policy designers, policy networks of experts and scholars, and national/local teacher education committees, and local provincial practitioners. In Chinese context, State council and Ministry of Education play a dominate role to guarantee RTSP to receive successful negotiations, which are very rare in other countries reforms of teacher careers, especially those that dramatically change rural teacher selection, rural teacher preparation, rural teacher recruitment, and rural teacher promotion. 
For more policy theories, the politics of RTSP offer solid foundation for modified various versions of some of the major arguments reviewed in the beginning of policy formation. In the power resource tradition, Chinese central government views RTSP as one key indicator to promote educational quality at national level. The policy networks were fundamental to design the reform subsequently, concentrating on the requirements for rural teacher development. Through the successive commissions, panels, and proposals, the policy network across foundations, think tanks, and universities reached a consensus on implementing rural teacher support plan with higher election standards, comprehensive improved training, stronger material and professional rewards, and regular evaluations to progress up the career development for rural teachers.

\section{References}

Chetty, R., Friedman, J. N., \& Rockoff, J. E. (2014). Measuring the Impacts of Teachers I: Evaluating bias in teacher value-added estimates. American Economic Review, 104(9), 2593-2632.

Corcoran, S. P. (2007). Long-run Trends in the Quality of Teachers: Evidence and implications for policy. Education Finance and Policy, 2(4), 395-407.

Guo, K., \& Kilderry, A. (2018). Teacher Accounts of Parent Involvement in Children's Education in China. Teaching and Teacher Education, 69, 95-103.

Li, J., Shi, Z., \& Xue, E. (2020). The Problems, Needs and Strategies of Rural Teacher Development at Deep Poverty Areas in China: Rural schooling stakeholder perspectives. International Journal of Educational Research, 99, 101496.

Li, J., Z. Yongzhi, X. Eryong \& N. Zhou, (2020). Faculty Ethics in China: From a historical perspective. Educational Philosophy and Theory, 52(2), 126-136.

Ministry of Education (2016, June 1). Rural Teacher Support Plan (2015-2020) http:// www.moe.gov.cn/jyb_xwfb/xw_zt/moe_357/jyzt_2016nztzl/ztzl_xyncs/ztzl_xy _zcfg/201701/t20170117_295043.html.

Osler, A., \& Starkey, H. (2017). Teacher Education and Human Rights. Routledge. 